\title{
Characterization of the Arginolytic Microflora Provides Insights into pH Homeostasis in Human Oral Biofilms
}

\author{
Xuelian Huang $^{\mathrm{a}}$ Renee M. Schulte ${ }^{\mathrm{c}}$ Robert A. Burne ${ }^{\mathrm{a}}$ \\ Marcelle M. Nascimento ${ }^{b}$ \\ ${ }^{a}$ Department of Oral Biology and ${ }^{b}$ Division of Operative Dentistry, Department of Restorative Dental Science, \\ College of Dentistry, University of Florida, and ${ }^{\complement}$ College of Dentistry, University of Florida, Gainesville, Fla., USA
}

\section{Key Words}

Arginine deiminase $\cdot$ Biofilm $\cdot$ Caries $\cdot$ Microflora $\cdot \mathrm{pH}$.

Plaque

\begin{abstract}
A selected group of oral bacteria commonly associated with dental health is capable of producing alkali via the arginine deiminase system (ADS), which has a profound impact on the $\mathrm{pH}$ of human oral biofilms. An increased risk for dental caries has been associated with reduced ADS activity of the bacteria in oral biofilms. Arginolytic bacterial strains from dental plaque samples of caries-free and caries-active adults were isolated and characterized to investigate the basis for differences in plaque ADS activity between individuals. Fiftysix ADS-positive bacterial strains were identified by $16 \mathrm{~S}$ rRNA gene sequencing, and their ADS activity levels were compared under standard growth conditions. The spectrum of bacterial ADS activity ranged from 45.2 to 688.0 units (mg protein $)^{-1}$. Although Streptococcus sanguinis was the most prevalent species, other Streptococcus sp. were also represented. Biochemical assays carried out using 27 ADS-positive strains under conditions known to induce or repress ADS gene expression showed substantial variation in arginolytic
\end{abstract}

activity in response to $\mathrm{pH}$, oxygen and the availability of carbohydrate or arginine. This study reveals that the basis for the wide spectrum of arginolytic expression observed among clinical strains is, at least in part, attributable to differences in the regulation of the ADS within and between species. The results provide insights into the microbiological basis for intersubject differences in ADS activity in oral biofilms and enhance our understanding of dental caries as an ecologically driven disease in which arginine metabolism moderates plaque $\mathrm{pH}$ and promotes dental health.

(c) 2015 S. Karger AG, Basel

Oral biofilms, often called dental plaque, constantly form and grow on all tooth surfaces. When conditions are favorable, dental biofilms are able to produce sufficient acids from carbohydrate fermentation to demineralize the tooth, leading to the formation of dental caries, the most prevalent infectious disease affecting humans. The transition from dental health to dental caries is characterized by compositional and metabolic changes in the complex microbial communities of oral biofilms. In particular, it is recognized that increases in the proportions of

\section{KARGER 125}

(c) 2015 S. Karger AG, Base

0008-6568/15/0492-0165\$39.50/0

E-Mail karger@karger.com

www.karger.com/cre
Marcelle M. Nascimento

Division of Operative Dentistry, Department of Restorative Dental Sciences College of Dentistry, University of Florida, 1395 Center Drive

Room D9-6, PO Box 100415, Gainesville, FL 32610-0415 (USA)

E-Mail mnascimento@ dental.ufl.edu 
aciduric organisms appear to occur at the expense of species that are less acid tolerant [Becker et al., 2002; Corby et al., 2005; Aas et al., 2008]. Importantly, a subset of abundant bacteria in dental biofilms derives protection from acidic conditions from the metabolism of substrates that yield alkaline products, and these species often show a strong positive correlation with dental health [Burne and Marquis, 2000].

The hydrolysis of urea and the catabolism of arginine are the primary sources of bacterially generated alkali in dental biofilms. Urea is present in relatively high concentrations (3-10 $\mathrm{mM}$ ) in human saliva and in gingival crevicular fluid [Golub et al., 1971; Kopstein and Wrong, 1977], and is rapidly hydrolyzed to 2 molecules of ammonia and 1 of $\mathrm{CO}_{2}$ by bacterial ureases. Although the anticaries effect of urea has been demonstrated in a rat model [Clancy et al., 2000], a variety of problems associated with urea have limited its utility as an anticaries agent in humans. Arginine is found free in saliva in micromolar concentrations [Van Wuyckhuyse et al., 1995] but is abundant in salivary peptides and proteins. Arginine is primarily catabolized by the arginine deiminase system (ADS) of oral bacteria into ornithine, ammonia and $\mathrm{CO}_{2}$, with the concomitant generation of ATP [Margolis et al., 1988; Van Wuyckhuyse et al., 1995; Burne and Marquis, 2000; Clancy et al., 2000]. Hence, the ADS serves key physiological functions in bacteria, providing protection from the deleterious effects of low $\mathrm{pH}$ while generating ATP for growth and maintenance [Vander Wauven et al., 1984; Marquis et al., 1987; Casiano-Colon and Marquis, 1988; Liu et al., 2008; Liu and Burne, 2009; Burne et al., 2010]. Notably, the ADS activity in oral biofilms can have major impacts on the ecology of oral microbial communities by moderating the $\mathrm{pH}$ through ammonia production [Vander Wauven et al., 1984; Marquis et al., 1987; Casiano-Colon and Marquis, 1988; Liu et al., 2008; Liu and Burne, 2009; Huang et al., 2012]. Inclusion of arginine in dentifrices or confections [Acevedo et al., 2005, 2008] was demonstrated to have significant effects in inhibiting caries, and the potential for the cost-effective use of this technology to reduce caries incidence and severity appears high. More recently, a number of studies, including 2-year randomized clinical trials, have shown that a dentifrice with arginine and fluoride was substantially better at preventing the initiation and progression of caries than fluoride alone [Kraivaphan et al., 2013; Srisilapanan et al., 2013; Yin et al., 2013a, b].

A variety of bacteria that are present in significant proportions in biofilms on the teeth and soft tissues of the oral cavity can express the ADS, including Streptococcus sanguinis, Streptococcus gordonii, Streptococcus parasanguis, Streptococcus mitis, Streptococcus oralis, Streptococcus rattus, certain Lactobacillus species and a few spirochetes [Marquis et al., 1987; Rogers, 1990; Burne and Marquis, 2000]. Knowledge derived from previous studies using laboratory strains of oral streptococci indicates that the expression of ADS genes is substrate inducible, sensitive to carbon catabolite repression and requires low $\mathrm{pH}$ and anaerobic conditions for optimal expression [Dong et al., 2004; Liu et al., 2008; Liu and Burne, 2009]. Specific and global transcriptional regulators, multiple 2-component systems and other factors have been shown to regulate ADS activity through transcriptional and posttranscriptional mechanisms [Burne, 1991; Dong et al., 2004; Liu et al., 2008; Liu and Burne, 2009].

Evidence continues to accumulate from in vitro and clinical observations that supports a significant influence of alkali generation on oral ecology and the inhibition of dental caries [Peterson et al., 1985; Margolis et al., 1988; Wijeyeweera and Kleinberg, 1989; Dawes and Dibdin, 2001; Shu et al., 2007; Nascimento et al., 2009]. A positive correlation between oral arginine metabolism and absence of caries activity has been demonstrated in adults [Nascimento et al., 2009] and more recently in children [Nascimento et al., 2013]. Specifically, oral bacteria from dental plaque of caries-free (CF) subjects present a higher ADS activity compared with those from caries-active (CA) subjects. From these studies, it was also evident that there is an exceptionally high degree of variability in the rate of ammonia production from arginine among individuals, in some cases greater than 1,000-fold. Importantly, an in vitro study showed that as little as a 5-fold decrease in the ammonia-generating capacity of a genetically modified strain of the caries pathogen Streptococcus mutans resulted in the loss of ability to offset environmental acidification by glycolysis [Clancy et al., 2000]. Therefore, many individuals may lack sufficient ADS activity to counteract dental plaque acidification. It is clear, then, that the ADS activity of plaque bacteria may greatly impact the $\mathrm{pH}$ profiles of resting and carbohydrate-challenged plaque, and therefore, the risk for caries development.

Differences in the microbial composition of oral biofilms and differential expression of the ADS are the most likely factors that affect the capacity of oral samples from different individuals to metabolize arginine. The use of quantitative PCR in a previous clinical study [Nascimento et al., 2009] did not reveal a statistically significant association between the proportions of 2 recognized arginolytic species, S. sanguinis and S. gordonii, and the caries 
status of adults. These results suggested that the diminution in ADS activity associated with caries experience may not be due simply to lower proportions of known ADS-positive bacteria, and also raised the possibility that species other than those examined may contribute to the overall oral ADS activity. It is also possible that environmental conditions and host factors encourage the differential expression of the ADS in CA versus CF subjects. Thus, there is a critical need to characterize more thoroughly the organisms that contribute to arginolysis in the oral cavity. To begin to understand the fundamental microbiology and ecology of oral arginolytic bacterial communities and their relationship to dental health and dental caries, the goals of the present study were to isolate and characterize arginolytic bacterial strains from supragingival dental plaque of CF and CA adult subjects, and to explore the responses of these strains to environmental stimuli.

\section{Materials and Methods}

\section{Isolation of Bacterial Strains}

Supragingival dental plaque was collected from $11 \mathrm{CF}$ subjects with no clinical or reported evidence of present or past caries experience [decayed, missing and filled teeth $($ DMFT $)=0$ ] and $3 \mathrm{CA}$ subjects with at least 4 active, cavitated (dentin level) and unrestored caries lesions ( DT $\geq 4, \mathrm{MFT} \geq 0$ ). The activity of caries lesions was determined by clinical appearance, plaque stagnation and tactile sensation. Informed consent was obtained from all participating subjects under a protocol reviewed and approved by the Institutional Review Board of the University of Florida Health Science Center. The criterion for collecting plaque samples was the same as described elsewhere [Nascimento et al., 2009]. To acquire a variety of cultivable microflora, plaque samples were dispersed by external sonication (W375, Sonicator Heat Systems-Ultrasonics Inc., Farmingdale, N.Y., USA) for 2 cycles of 15 s, with cooling on ice during the interval. Samples were then serially diluted in 10 $\mathrm{mM}$ sodium phosphate buffer ( $\mathrm{pH} 7.0)$, and $100 \mu \mathrm{l}$ of the $10^{-4}$ to $10^{-7}$ diluted samples were cultured on sheep blood agar plates (Columbia Agar containing 5\% V/V of anticoagulated sheep blood, Difco Laboratories, Detroit, Mich., USA) and on brainheart infusion agar plates (Difco Laboratories). Plates were incubated at $37^{\circ} \mathrm{C}$ in anaerobic jars (BBL GasPak ${ }^{\mathrm{TM}}$ Systems, BD Diagnostics, Sparks, Md., USA) for 3 days with subsequent aerobic incubation at $37^{\circ} \mathrm{C}$ in $5 \% \mathrm{CO}_{2}$ for 2 days. After the incubation period, colonies of clinical strains representing all morphological types were subcultured on the same media until pure colonies were obtained.

\section{Screening of ADS-Positive Strains}

Bacterial strains were screened for the potential to liberate ammonia from arginine in a microtiter-based assay [Schulte et al., 2009]. Briefly, strains were grown in clear polystyrene microtiter plates (Fisher Scientific Inc., USA) containing tryptone-vitaminbased broth [Burne et al., 1999] with $0.2 \%$ galactose and $10 \mathrm{mM}$ arginine. The plates were incubated under anaerobic conditions $\left(85 \% \mathrm{~N}_{2}, 5 \% \mathrm{CO}_{2}, 10 \% \mathrm{H}_{2}, 80 \%\right.$ relative humidity) at $37^{\circ} \mathrm{C}$ for $48 \mathrm{~h}$. Bacterial cells were collected by centrifuging the plates for $3 \mathrm{~min}$ at $10,000 \mathrm{~g}$ in a refrigerated microcentrifuge, washed once with $10 \mathrm{~mm}$ Tris-maleate ( $\mathrm{pH} 7.0)$ and resuspended in $100 \mu \mathrm{l}$ of $50 \mathrm{~mm}$ Tris-maleate buffer ( $\mathrm{pH}$ 6.0). The ADS-positive phenotype was identified by detecting the ammonia generated from the incubation of bacteria in the presence of $50 \mathrm{mM}$ arginine- $\mathrm{HCl}$ for $2 \mathrm{~h}$ at $37^{\circ} \mathrm{C}$ using Nessler's reagent (Sigma-Aldrich Inc., USA). Controls for background and interference were routinely included in each reaction. The library of the ADS-positive strains was stored at $-80^{\circ} \mathrm{C}$ for further analysis. From this library, 56 ADS-positive strains were randomly selected from the plaque of the various $\mathrm{CF}$ and CA subjects to be identified by $16 \mathrm{~S}$ rRNA gene sequencing and characterized in this study.

\section{Amplification and Sequencing of 16S rRNA Genes by PCR}

An optimized colony PCR reaction was used to amplify $16 \mathrm{~S}$ rRNA genes. Colonies were picked up with a sterilized pipette tip and directly transferred to the tubes for the PCR reaction. Sequences of the $16 \mathrm{~S}$ rRNA genes were amplified under standardized conditions using a universal primer set (forward: $5^{\prime}$-AGA GTT TGA TCC TGG CTC AG-3', reverse: $5^{\prime}$-TAC GGG TAC CTT GTT ACG ACT-3') [Paster et al., 2001; Aas et al., 2005]. DNA purification was carried out using the QIAprep spin miniprep kit purchased from Qiagen Inc. (Valencia, Calif., USA). Purified PCR products of $16 \mathrm{~S}$ rRNA were sequenced using an ABI Prism cycle sequencing kit and the primers and conditions and the data analyzed as previously described [Paster et al., 2001; Aas et al., 2005]. DNA sequences were compared to the $16 \mathrm{~S}$ rRNA sequences deposited at the Human Oral Microbiome Database, Ribosomal Database Project and the GenBank database. The complete 16S rRNA gene sequences generated in this study will be available for electronic retrieval from the EMBL, GenBank and DDBJ nucleotide sequence databases.

\section{ADS Activity, Growth Conditions and Reagents}

ADS activity of bacterial strains was measured by monitoring citrulline production from arginine using protocols validated by our group [Liu et al., 2008]. Bacterial strains were maintained on fresh brain-heart infusion agar and inoculated into tryptoneyeast (TY) extract broth containing $25 \mathrm{mM}$ galactose and $10 \mathrm{mM}$ arginine for overnight growth in a $5 \% \mathrm{CO}_{2}$ aerobic atmosphere at $37^{\circ} \mathrm{C}$. ADS activity of the 56 selected ADS-positive strains was determined under the following standard growth conditions: overnight cultures of each strain were diluted (1:20 dilution) into fresh TY medium containing $25 \mathrm{mM}$ galactose and $10 \mathrm{~mm}$ arginine and incubated as above until the $\mathrm{OD}_{600}$ reached 0.5-0.6 [Liu et al., 2008]. The cells were then permeabilized in toluene-acetone (1:9) prior to determination of their ADS activity. The concentration of protein in the permeabilized cell preparations was determined using a Pierce BCA protein assay kit (Waltham, Mass., USA) with bovine serum albumin as the standard. ADS activity levels of bacterial strains were normalized to protein content and defined as nanomoles of citrulline generated per minute per milligram protein.

To monitor ADS expression as a function of environmental conditions known to induce or repress the ADS, 27 representatives of different bacterial species were grown in TY base medium containing: $25 \mathrm{mM}$ galactose with or without $10 \mathrm{mM}$ arginine; $25 \mathrm{mM}$ 
galactose and $10 \mathrm{~mm}$ arginine that had been acidified to $\mathrm{pH} 5.7$ with $\mathrm{HCl}$ or buffered at $\mathrm{pH} 7.0$ with $50 \mathrm{~mm}$ potassium phosphate buffer (with TY); $10 \mathrm{mM}$ arginine and $25 \mathrm{mM}$ galactose or $25 \mathrm{mM}$ glucose; or $25 \mathrm{mM}$ galactose and $10 \mathrm{mM}$ arginine with the cultures incubated under aerobic or anaerobic conditions. For aerobic growth, the cells were inoculated into a 250 -ml conical flask containing $40 \mathrm{ml}$ of TY medium supplemented with galactose and arginine and grown on a rotary shaker $\left(50\right.$ r.p.m.) at $37^{\circ} \mathrm{C}$. For anaerobic growth, cultures were similarly diluted and incubated in an anaerobic chamber at $5 \% \mathrm{CO}_{2}, 10 \% \mathrm{H}_{2}, 85 \% \mathrm{~N}_{2}$ and $37^{\circ} \mathrm{C}$. All the cells were collected at $\mathrm{OD}_{600}=0.5-0.6$ for the detection of ADS activity.

\section{Statistical Analysis}

For descriptive analysis, distribution of percentages and means were calculated when appropriate. Student's t test or ANOVA were used to test the differences of continuous variables, and the $\chi^{2}$ test was used for categorical variables. The correlation between the proportions of ADS-positive bacterial strains and total cultivable organisms with the subjects' caries status was analyzed using the two-proportions $\mathrm{Z}$ test. The level of significance was determined at $\mathrm{p}<0.05$.

\section{Results}

\section{Arginolytic Bacterial Strains of Oral Biofilms}

A total of 2,328 bacterial strains were isolated from plaque samples of the 14 participating subjects ( $11 \mathrm{CF}$ and $3 \mathrm{CA}$; ratio of 166.3 strains isolated per subject), and screened for arginolytic capacity by detection of ADS activity. Of these 2,328 strains, 288 were ADS-positive, which represents a ratio of 20.5 strains per subject, or 15.8 strains per CF subject (minimum of 5 ADS-positive and maximum of 51 ADS-positive strains within this caries group) and 38 strains per CA subject (minimum of 6 ADS-positive and maximum of 84 ADS-positive strains within this caries group). Despite considerable variation among the number of ADS-positive strains identified within subjects and within the caries groups, there was a fair or unbiased distribution of the strains tested across subjects. There was no significant correlation between the proportions of ADS-positive strains in the total cultivable flora with the caries status of the subjects.

Table 1 shows the diversity of arginolytic species isolated from supragingival dental plaque and identified by $16 \mathrm{~S}$ rRNA gene sequencing. All 56 ADS-positive strains identified had greater than $99 \%$ sequence similarity with their assigned bacterial taxa. A total of 6 different bacterial taxa of Streptococcus representing the bacterial phylum Firmicutes were detected: S. sanguinis (67.9\%), S. gordonii (8.9\%), Streptococcus intermedius (8.9\%), Streptococcus cristatus (8.9\%), Streptococcus australis (3.6\%) and
S. parasanguinis $(1.8 \%)$. The spectrum of bacterial ADS activity ranged from 45.2 to 688.0 units ( $\mathrm{mg}$ protein $)^{-1}$ when bacterial cells were incubated under standard growth conditions. The ADS activity of clinical strains of S. sanguinis varied from 45.2 to 263.4 units (mg protein $)^{-1}$. Of note, higher ADS activity was observed among strains of S. parasanguinis, S. intermedius, S. gordonii and S. australis, when compared to strains of $S$. sanguinis and $S$. cristatus. There was no statistical difference between the average of bacterial ADS activity among the caries groups, despite the fact that, on average, arginolytic strains of CF subjects [200.2 units (mg protein) ${ }^{-1}$ ] presented slightly higher activity compared to those of CA subjects [188.1 units (mg protein $\left.)^{-1}\right)$ ] under standard growth conditions.

\section{ADS Expression as a Function of Environmental Stimuli}

A substantial variation in ADS expression patterns was observed in response to $\mathrm{pH}$, oxygen and the availability of arginine and carbohydrate as illustrated in figures 1 and 2. Figure 1a shows that for most strains, including the laboratory strain S. gordonii DL1, optimal expression of ADS was strongly dependent on the presence of arginine. However, strains such as $S$. parasanguinis A1, S. intermedius A2 and A3, S. gordonii A8 and S. australis A12 and A13 demonstrated higher ADS expression compared to $S$. gordonii DL1, even in the absence of arginine. Also of note, a number of the strains presented high levels of ADS in the absence of added arginine, including $S$. parasanguinis A1, S. intermedius A3, and S. australis A12 and A13.

A low $\mathrm{pH}$ environment is known to enhance ADS activity in S. gordonii DL1; however, S. intermedius A3, S. gordonii A8 and S. australis A12 expressed significantly higher levels of ADS activity than S. gordonii when cells were cultured at neutral $\mathrm{pH}$ (fig. 1b) and did not show evidence of induction at $\mathrm{pH}$ 5.7. In contrast, S. parasanguinis A1 showed very high levels of ADS activity at that $\mathrm{pH}$, and significant induction at $\mathrm{pH} 5.7$ was observed.

Expression of the genes for the ADS of S. gordonii DL1 is also very sensitive to carbon catabolite repression [Dong et al., 2004], with growth in glucose resulting in 5 -fold lower ADS activity compared to cells cultivated in galactose [Dong et al., 2004], which is less effective at eliciting carbon catabolite repression than glucose. Similarly, glucose could lower ADS activity of all the clinical strains to varying degrees (fig. 1c). Yet strains such as $S$. parasanguinis A1, S. intermedius A2, A3 and A5, S. gordonii A7, 


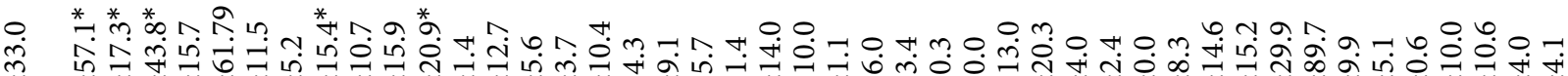

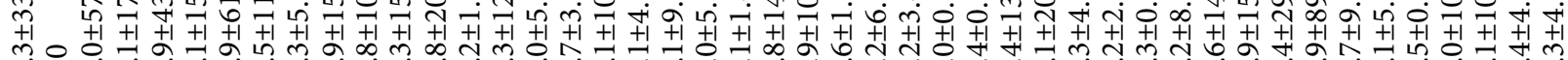

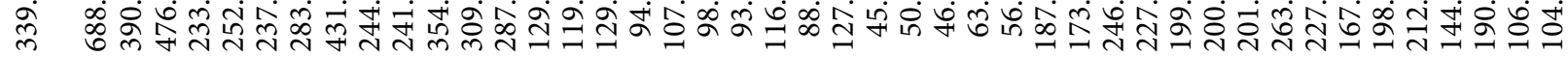

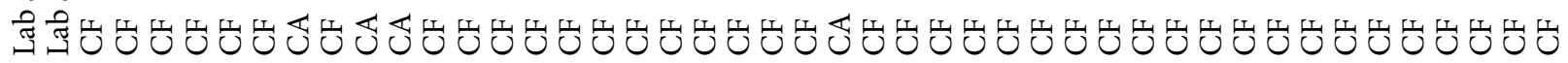
焉忈

$\stackrel{\infty}{\infty}$

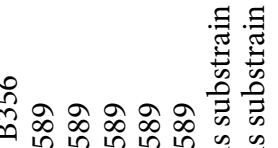

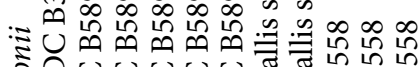

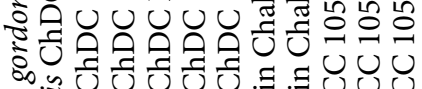

$\overrightarrow{\mathrm{d}}$

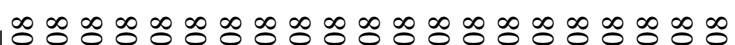

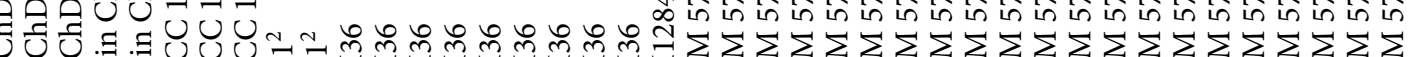

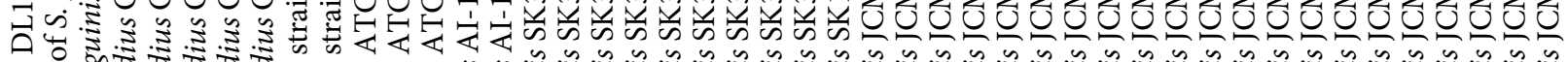

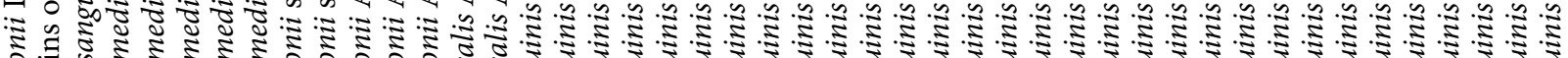

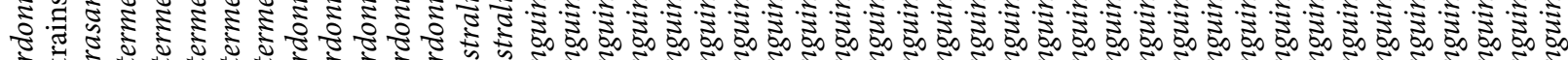

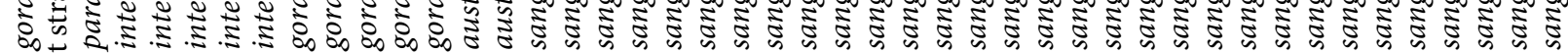

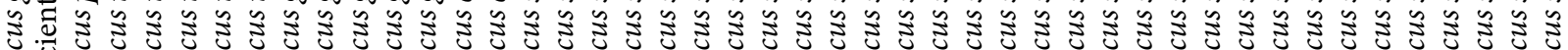
o

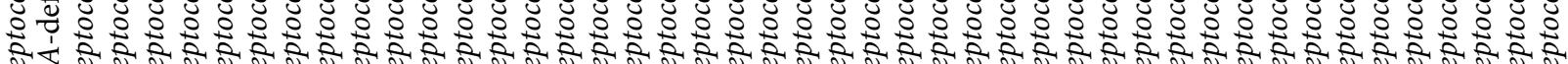

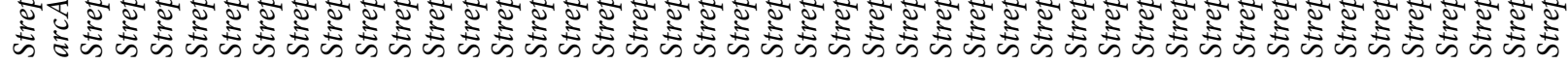

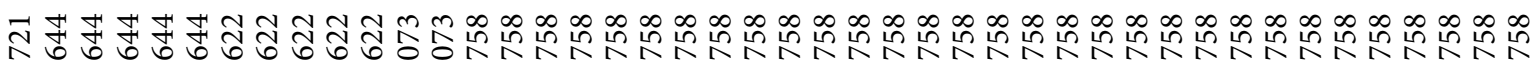

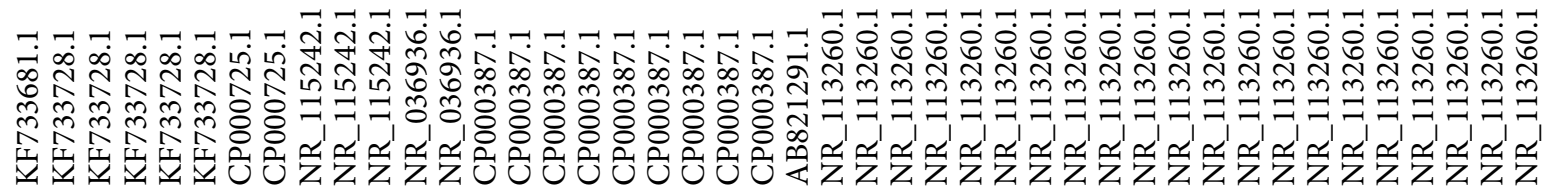

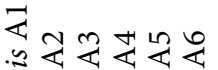

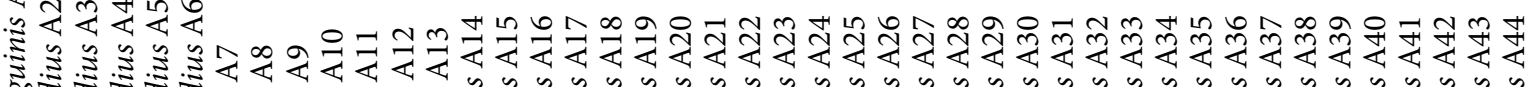

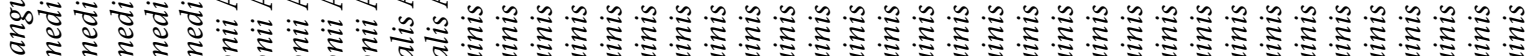

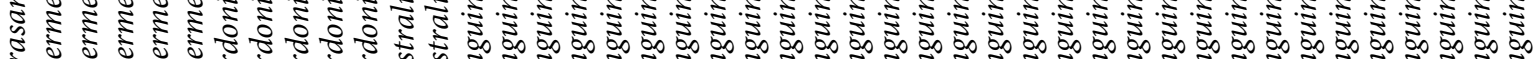
है. है.

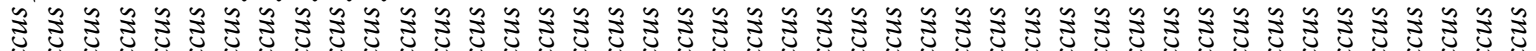

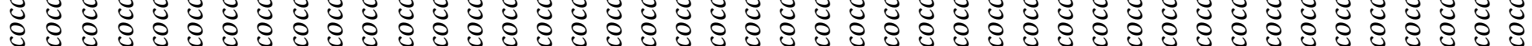

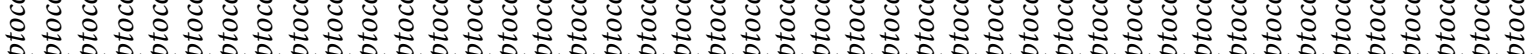

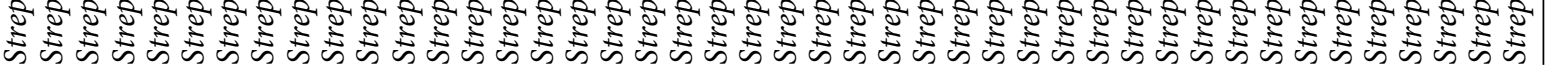




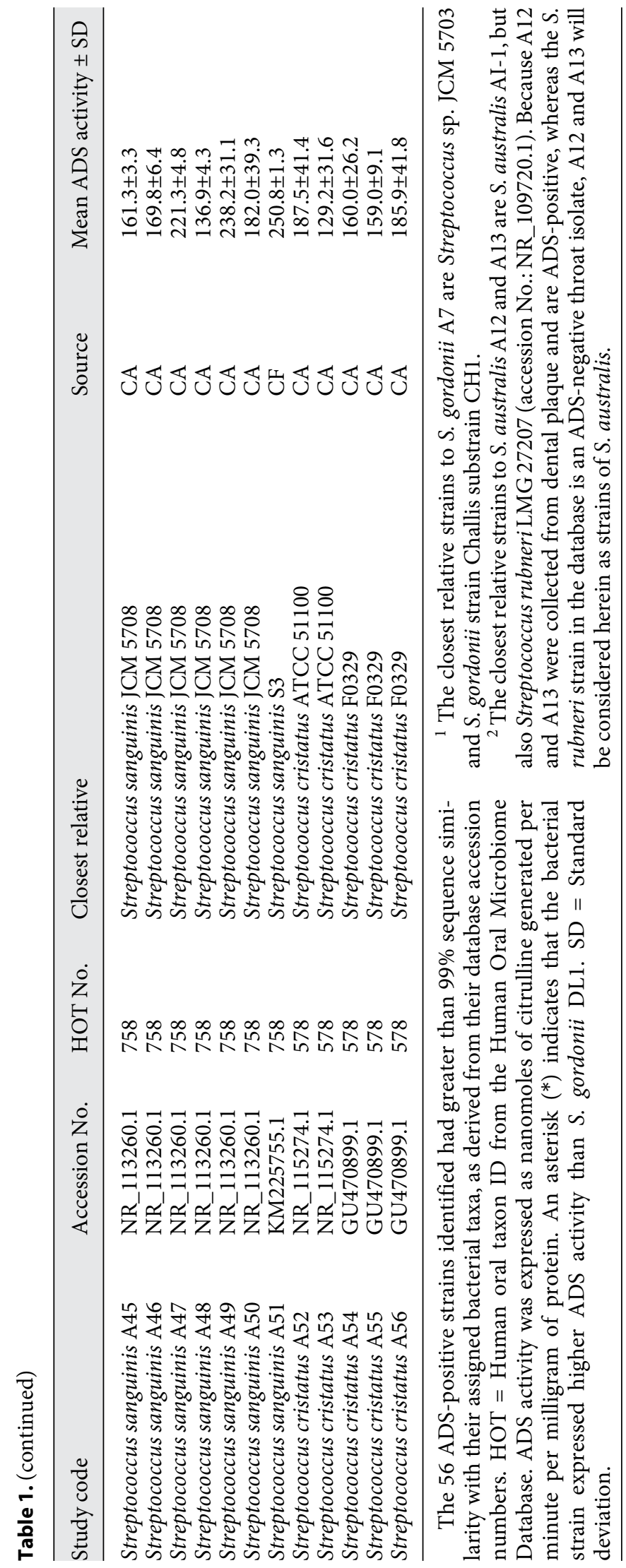

A8, A9, A10 and A11, and S. australis A12 and A13 exhibited ADS activity that was higher than that expressed by S. gordonii DL1 when cells were grown in the presence of $25 \mathrm{~mm}$ glucose.

Figure $1 \mathrm{~d}$ confirms that expression of ADS activity by S. gordonii DL1 was highly repressed in cells growing under aerobic conditions and similar repression by oxygen was noted in the majority of clinical strains. However, ADS activity in S. intermedius A2, A3 and A5, and in S. sanguinis A51 were either far less sensitive to, or resistant to the repressive effects of growth in aerated conditions.

Intraspecies heterogeneity was also highlighted by further phenotypic characterization of the clinical strains studied here (data not shown). For example, 16 S sequencing revealed that the closest relative strains in the database to S. gordonii A7 are Streptococcus sp. JCM 5703 and $\mathrm{S}$. gordonii strain Challis substrain $\mathrm{CH} 1$. However, phenotypically, the $\mathrm{A} 7$ strain is able to produce $\mathrm{H}_{2} \mathrm{O}_{2}$ from lactate, a property that is also found in A9, A10 and A11 strains, which are most similar at the $16 \mathrm{~S}$ level to $S$. gordonii 10558. Unlike the A7, A9, A10 and A11 strains, the A8 strain, which at the $16 \mathrm{~S}$ level is most similar to S. gordonii strain Challis substrain $\mathrm{CH} 1$, does not exhibit the capacity of producing $\mathrm{H}_{2} \mathrm{O}_{2}$ from lactate.

\section{ADS Expression and Caries Status}

As shown in table 1, different levels of ADS activity were observed among strains of the same species isolated from plaque of $\mathrm{CF}$ and CA subjects. For example, the strains S. sanguinis A48 [136.9 units (mg protein) ${ }^{-1}$ ] and S. gordonii A7 [283.3 units (mg protein $)^{-1}$ ]) from CA subjects and S. sanguinis A36 [263.4 units (mg protein) $)^{-1}$ ] and S. gordonii A8 [431.9 units (mg protein $)^{-1}$ ] from CF subjects presented different ADS expression under standard growth conditions, respectively. To further explore whether the arginolytic capacity of oral bacteria was related to the caries status of the subjects, we compared

Fig. 1. ADS activity levels of S. gordonii DL1 and arginolytic clinical strains under different environmental conditions. Cultures of TY medium containing: $25 \mathrm{mM}$ galactose with or without $10 \mathrm{mM}$ arginine (a), $25 \mathrm{~mm}$ galactose and $10 \mathrm{~mm}$ arginine that had been acidified to $\mathrm{pH} 5.7$ with $\mathrm{HCl}$ or buffered at $\mathrm{pH} 7.0$ (b), Cultures of TY medium containing: $10 \mathrm{mM}$ arginine and $25 \mathrm{mM}$ galactose or $25 \mathrm{~mm}$ glucose (c), and $25 \mathrm{~mm}$ galactose and $10 \mathrm{~mm}$ arginine, where the cells were cultured under aerobic (with $\mathrm{O}_{2}$ ) or anaerobic (without $\mathrm{O}_{2}$ ) conditions (d). Results represent the mean and standard deviations (error bars) of 3 independent experiments.

(For figure 1 see next page.) 


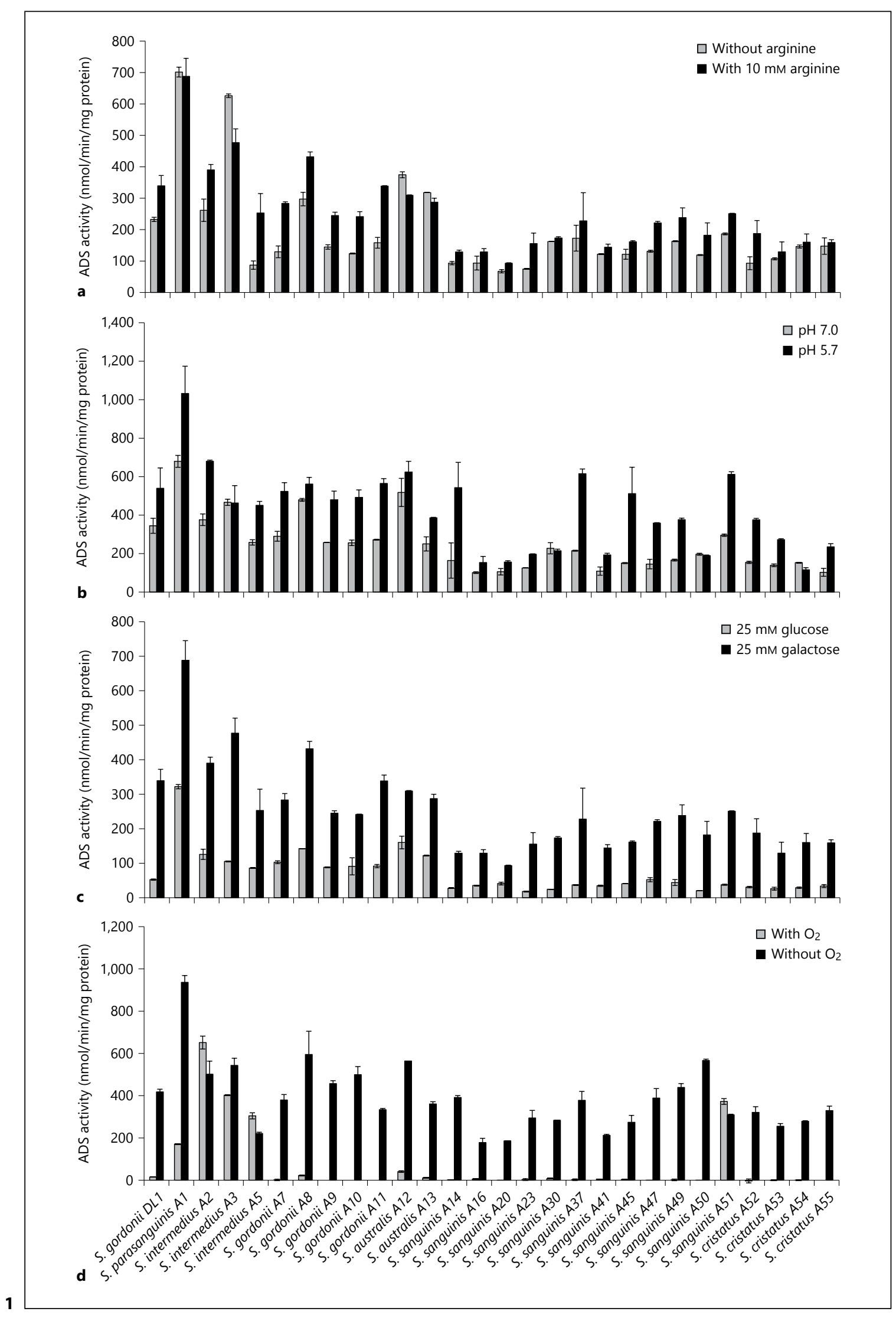




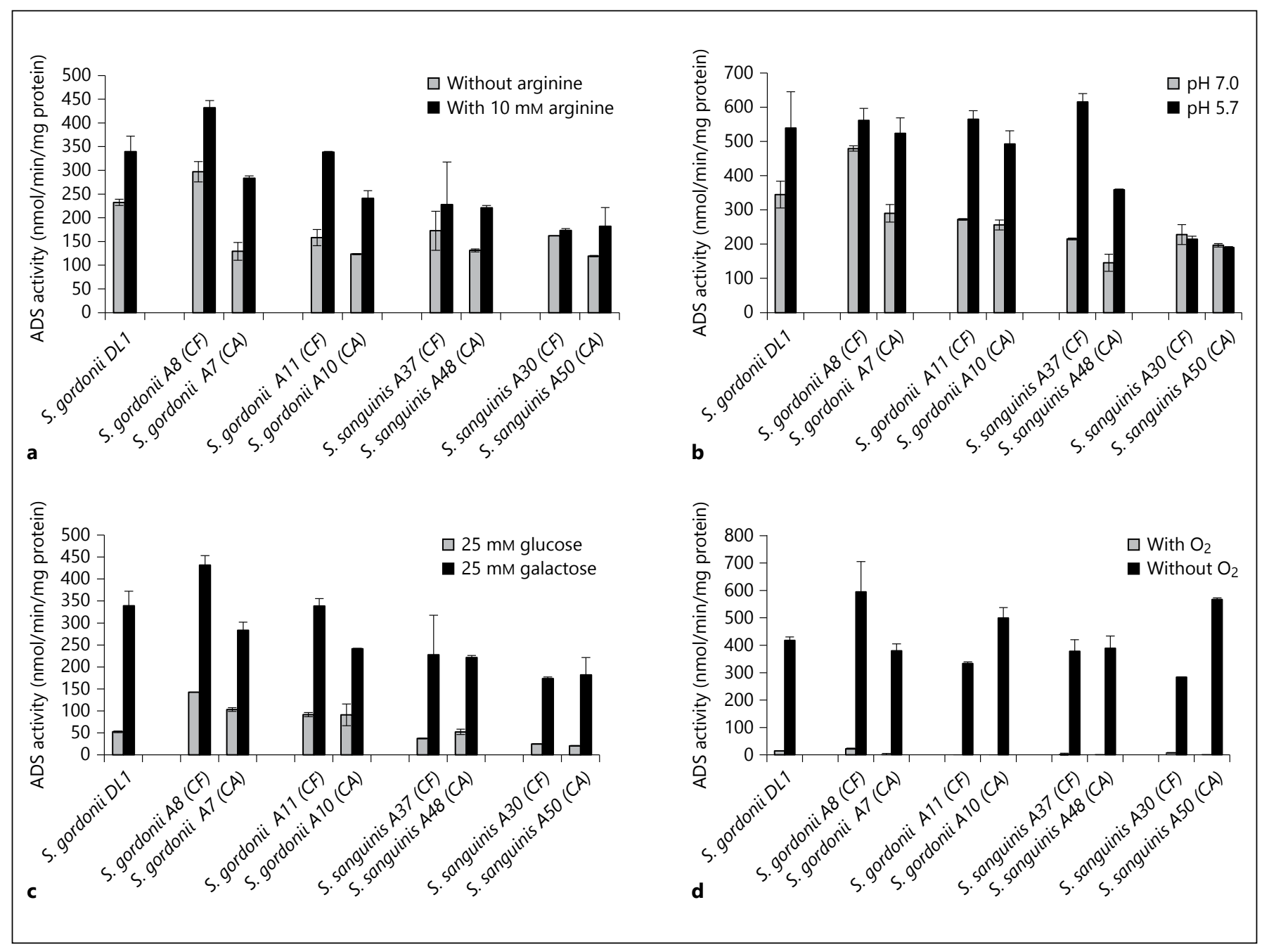

Fig. 2. Comparison of the ADS activity levels of arginolytic strains from CA and CF subjects grown under different environmental conditions. Cultures of TY medium containing: $25 \mathrm{mM}$ galactose with or without $10 \mathrm{~mm}$ arginine (a), $25 \mathrm{~mm}$ galactose and $10 \mathrm{mM}$ arginine that had been acidified to $\mathrm{pH} 5.7$ with $\mathrm{HCl}$ or buffered at
pH 7.0 (b), $10 \mathrm{~mm}$ arginine and $25 \mathrm{~mm}$ galactose or $25 \mathrm{mM}$ glucose (c), and $25 \mathrm{mM}$ galactose and $10 \mathrm{mM}$ arginine where the cells were cultured under aerobic (with $\mathrm{O}_{2}$ ) or anaerobic (without $\mathrm{O}_{2}$ ) conditions (d). Results represent the mean and standard deviations (error bars) of 3 independent experiments.
ADS expression in response to different environmental conditions for clinical strains of the same species isolated from the different caries groups (fig. 2). The selected strains included those with the highest 16S rRNA sequence similarity to $\mathrm{S}$. gordonii Challis substrain $\mathrm{CH} 1$ (A7 and A8), S. gordonii ATCC 10558 (A10 and A11), S. sanguinis JCM 5708 (A37 and A38), and S. sanguinis JCM 5708 (A30 and A50).

Figure 2a shows that most strains of the same species presented comparable differences in ADS expression in response to arginine independently of the subjects' caries status. For example, both S. gordonii A10 from a CA sub- ject and S. gordonii A11 from a CF subject showed an about twice as high ADS activity in the presence of arginine compared to growth in the absence of arginine. The exception was with the S. sanguinis A30 and A50 strains. While the expression levels of ADS were generally similar between the two strains, ADS expression in S. sanguinis A30 from a CF subject did not require supplemental arginine for optimal expression of the ADS, whereas S. sanguinis A50 did.

Similar patterns for ADS expression and induction by acidic $\mathrm{pH}$ were observed among strains of S. gordonii A7 and A8, S. gordonii A10 and A11, and S. sanguinis A37 
and A38 from both caries groups (fig. 2b). The exception was again for the $S$. sanguinis A30 and A50 strains, where S. sanguinis A30 from a CF subject and S. sanguinis A50 from a CA subject showed no induction of ADS by low $\mathrm{pH}$, compared to neutral $\mathrm{pH}$. In contrast to effects of arginine and $\mathrm{pH}$, all strains of S. gordonii and S. sanguinis from both caries groups showed a similar pattern of ADS repression by glucose (fig. 2c) and ADS repression by oxygen (fig. 2d).

\section{Discussion}

Arginine metabolism in oral biofilms offers the opportunity for the development of novel anticaries approaches that may be beneficial for short-term moderation of acid challenges to teeth and long-term effects on the persistence of desirable bacteria in dental plaque. However, if arginolysis is to be used in the development of strategies to assess caries risk and to control caries, there is a need to fully understand the distribution, regulation and function of the ADS in oral biofilms in health and disease. Although genome sequencing and other molecular techniques have revealed new levels of complexity in the cariogenic microflora and in the nature of individual bacterial species [Mager et al., 2003; Corby et al., 2005; Aas et al., 2008; Russell, 2008; Crielaard et al., 2011], limited attempts [Sissons et al., 1988a, b, 1994] have been made to identify and characterize the clinically relevant oral organisms capable of producing alkali that can potentially diminish the cariogenicity of oral biofilms. In this study, a rapid and simple protocol was developed for screening of cultivable arginolytic bacteria isolated from dental plaque samples. Even though the majority of the ADS-positive bacterial species identified were strains of S. sanguinis, additional cultivable species including S. gordonii, S. intermedius, S. cristatus, S. australis and S. parasanguinis were shown to be present and to have the potential to contribute to different extents to total oral ADS activity. In conjunction with previous and extensive microbiological studies demonstrating the abundance in human oral biofilms of the commensal streptococci that were identified here [Mager et al., 2003; Corby et al., 2005; Aas et al., 2005, 2008; Dewhirst et al., 2010; Gross et al., 2010; Crielaard et al., 2011], our results reveal that these abundant streptococci likely have a dominant influence on the arginolytic capacity of human oral biofilms. Importantly, this study clearly demonstrates that the ADS of clinical strains is in fact regulated in response to those specific environmental factors that have the greatest im- pact on the composition and biochemical activities of supragingival biofilms; for instance, availability and source of carbohydrate, low $\mathrm{pH}$ and oxygen are all well-recognized environmental factors that can influence the development of caries.

The diversity of the oral microbiota associated with health and disease is only beginning to be described by high-throughput methodologies [Mager et al., 2003; Corby et al., 2005; Aas et al., 2008; Gross et al., 2010; Crielaard et al., 2011]. While this species- or taxon-level identification is tremendously valuable [Dewhirst et al., 2010], it does not address the fact that there is significant heterogeneity within given species of oral bacteria. Based on current sequencing efforts, the majority of ADS-positive oral bacterial species are cultivable and mostly consist of abundant oral streptococci. Although uncultivable organisms may contribute to the total arginolytic activity measured in oral biofilms, organisms that were unlikely to grow under the conditions we used to cultivate plaque samples generally do not possess the ADS [Nascimento and Burne, unpubl. observation] or are not well represented in supragingival plaque, e.g. certain spirochetes. Further, many uncultivable bacterial species are represented in plaque in far lower proportions than cultivable species [Mager et al., 2003; Corby et al., 2005; Aas et al., 2008; Gross et al., 2010; Crielaard et al., 2011]. Thus, one would expect that the contribution to the total ADS of uncultivable organisms is minor at best. Importantly, the present study enhances ongoing oral microbiome efforts by highlighting the phenotypic heterogeneity of the more abundant species in the oral cavity in the context of their abilities to modulate the $\mathrm{pH}$, and thus the cariogenic potential, of oral biofilms. This study also presents novel theoretical concepts - the molecular basis for heterogeneity in alkali production - while concurrently generating knowledge, strains, probes and reagents that will advance existing methodologies for evaluating and understanding the pathogenic potential of the oral microbiome.

Markedly less is known about the production of alkali than is known about sugar metabolism in oral biofilms. The causal relationship between bacterial sugar metabolism and acid production by a mixed population of plaque bacteria was first described by Stephan [1940]. Stephan also pointed out that the drop in plaque $\mathrm{pH}$ detected after sugar challenge is followed by a gradual rise in plaque $\mathrm{pH}$ that eventually reaches a plateau. Later, the plateau - or resting $\mathrm{pH}$ - of CA plaque was found to be more acidic than that of CF plaque [Margolis et al., 1988], further supporting a correlation between acid production and dental 
caries. Subsequent studies showed that the rise in plaque $\mathrm{pH}$ is largely due to ammonia production from arginine or urea by a subset of acid-sensitive organisms present in saliva and plaque [Wijeyeweera and Kleinberg, 1989]. Marquis [1995] suggested that the buffering capacity from ammonia production in oral biofilms moderates the speed of the $\mathrm{pH}$ drop and allows time for the base-producing bacteria to adjust their physiology for survival. Kleinberg and Jenkins [1964] showed that carbohydratestarved plaque was more alkaline than the saliva bathing the plaque, mainly in regions of greater saliva flow, so it was suggested that plaque bacteria generate ammonia from salivary substrates more rapidly than the forces of diffusion can clear them from dental plaque. Kleinberg [1970] also foretold that the plaque $\mathrm{pH}$ would be determined by the acid-base metabolism of plaque organisms, which in turn could be affected by plaque thickness, the proportions of acid- and base-producing organisms in plaque, and the relative availability of nitrogenous and carbohydrate substrates.

Our clinical studies support our clinical studies support that caries susceptibility involves a deficiency in alkali production and not solely acid production, as has been traditionally assumed [Shu et al., 2007; Nascimento et al., 2009, 2013]. Here, we began to examine whether the heterogeneity of oral bacterial strains, the constitutional difference in the ADS gene expression levels and/ or differential sensitivity of the ADS genes to induction or repression by environmental factors could account for the high degree of variability in alkali production detected in dental health and when caries activity is evident. Although ADS-positive strains from CF subjects showed slightly higher levels of ADS activity than those isolated from CA subjects, there was no significant correlation between levels of bacterial ADS activity and the caries status of the host. Yet, this study examining a collection of arginolytic plaque bacteria, or more specifically the ADS activity in closely related commensal streptococci, revealed a considerable spectrum of responses of the ADS to multiple environmental stimuli. While control of expression and activity of the ADS in vivo may be more complex and involve more inputs than tested here, the results clearly show that differences in the regulation of the ADS and absolute levels of ADS activity exist in the most abundant members of the commensal flora. Thus, it is possible that the basis for differences in arginolysis observed between CF and CA subjects can be associated with: (i) the carriage in oral biofilms of strains that have inherent differences in the regulation of the ADS by environmental factors and/or (ii) host and biofilm microenvironmental factors that influence ADS expression in vivo. For example, the biofilms of CA subjects may not be conducive to high ADS expression or may produce inhibitory factors that decrease ADS gene expression or activity. Clearly, arginolytic clinical strains with constitutionally high ADS-expressing phenotypes and those in which ADS expression is insensitive to conditions known to cause dental caries - sugar availability and acidic environment - may have great potential in probiotic therapies to prevent and control dental caries.

In conclusion, this study reveals that the microbial basis for intrasubject variation in oral arginolysis is more complex than previously appreciated; not only may the arginolytic potential of oral biofilms be associated with the carriage of certain strains of bacteria, but also arginolytic species display a range of ADS activity as a function of environmental variables. The results are significant in the context of understanding caries as an ecologically driven disease by supporting that high ADS-expressing strains could positively affect plaque ecology in a synergistic manner, i.e. by moderating plaque $\mathrm{pH}$ and reducing the risk for caries. This study has expanded the knowledge on the diversity of the oral alkali-generating bacteria and, potentially on their role in oral health and disease. Future studies will assess whether there are associations of particular strains possessing beneficial properties with dental health, or if particular strains with undesirable properties - high aciduricity, low arginolysis, poor antagonism against acidogenic organisms - are associated with disease. Undoubtedly, a better understanding of the microbial composition of plaque and its $\mathrm{pH}$ responses is needed in order to efficiently reduce the cariogenicity of oral biofilms.

\section{Acknowledgments}

We thank Yaling Liu and Roshan Kalra for their contributions to the development and refinement of some of the methodologies utilized in this study. This work was supported by Colgate-Palmolive and NIH/NIDCR R01-DE10362, K23-DE023579 and R90DE022530.

\section{Author Contributions}

M.M. Nascimento and R.A. Burne designed the study. M.M. Nascimento performed the clinical examinations for recruitment of research subjects and collected dental plaque samples from the eligible subjects. R.M. Schulte isolated the bacterial 
strains from the plaque samples. X. Huang performed all the biochemical and molecular biology assays of the study and analyzed the raw data. X. Huang, R.A. Burne and M.M. Nascimento evaluated and interpreted the data, and wrote the manuscript.

\section{Disclosure Statement}

The authors declare that there are no conflicts of interest.

\section{References}

- Aas JA, Griffen AL, Dardis SR, Lee AM, Olsen I, Corby PM, Lyons-Weiler J, Bretz WA, Hart TC, Dewhirst FE, Leys EJ, Paster BJ: Bacteria of dental caries in primary and permanent teeth in children and young adults. J Clin Microbiol 2008;46:1407-1417.

-Aas JA, Paster BJ, Stokes LN, Olsen I, Dewhirst FE: Defining the normal bacterial flora of the oral cavity. J Clin Microbiol 2005;43:57215732.

Acevedo AM, Machado C, Rivera LE, Wolff M, Kleinberg I: The inhibitory effect of an arginine bicarbonate/calcium carbonate cavistatcontaining dentifrice on the development of dental caries in Venezuelan school children. J Clin Dent 2005;16:63-70.

-Acevedo AM, Montero M, Rojas-Sanchez F, Machado C, Rivera LE, Wolff M, Kleinberg I: Clinical evaluation of the ability of cavistat in a mint confection to inhibit the development of dental caries in children. J Clin Dent 2008; 19:1-8.

Becker MR, Paster BJ, Leys EJ, Moeschberger ML, Kenyon SG, Galvin JL, Boches SK, Dewhirst FE, Griffen AL: Molecular analysis of bacterial species associated with childhood caries. J Clin Microbiol 2002;40:1001-1009.

Burne R, Liu Y, Zeng L: Acid tolerance strategies of commensal and pathogenic oral streptococci. Soc Gen Microbiol Autumn 2010 Meet, Nottingham, 2010.

- Burne RA, Marquis RE: Alkali production by oral bacteria and protection against dental caries. FEMS Microbiol Lett 2000;193:1-6.

Burne RA, Parsons DT, Marquis RE: Environmental variables affecting arginine deiminase expression in oral streptococci; in Dunny G, Cleary P, McKay L (eds): Genetics and Molecular Biology of Streptococci, Lactococci, and Enterococci. Washington, American Society for Microbiology, 1991.

Burne RA, Wen ZT, Chen YY, Penders JE: Regulation of expression of the fructan hydrolase gene of Streptococcus mutans gs- 5 by induction and carbon catabolite repression. J Bacteriol 1999;181:2863-2871.

-Casiano-Colon A, Marquis RE: Role of the arginine deiminase system in protecting oral bacteria and an enzymatic basis for acid tolerance. Appl Environ Microbiol 1988;54:13181324.

Clancy KA, Pearson S, Bowen WH, Burne RA: Characterization of recombinant, ureolytic Streptococcus mutans demonstrates an inverse relationship between dental plaque ureolytic capacity and cariogenicity. Infect Immun 2000;68:2621-2629. Aas JA, Boumenna T, Goss J, Corby AL, Junior HM, Weyant RJ, Paster BJ: Microbial risk indicators of early childhood caries. J Clin Microbiol 2005;43:5753-5759.

-Crielaard W, Zaura E, Schuller AA, Huse SM, Montijn RC, Keijser BJ: Exploring the oral microbiota of children at various developmental stages of their dentition in the relation to their oral health. BMC Med Genomics 2011;4:22.

Dawes C, Dibdin GH: Salivary concentrations of urea released from a chewing gum containing urea and how these affect the urea content of gel-stabilized plaques and their $\mathrm{pH}$ after exposure to sucrose. Caries Res 2001;35:344353.

Dewhirst FE, Chen T, Izard J, Paster BJ, Tanner AC, Yu WH, Lakshmanan A, Wade WG: The human oral microbiome. J Bacteriol 2010; 192:5002-5017.

Dong Y, Chen YY, Burne RA: Control of expression of the arginine deiminase operon of Streptococcus gordonii by CcpA and Flp. J Bacteriol 2004;186:2511-2514.

Golub LM, Borden SM, Kleinberg I: Urea content of gingival crevicular fluid and its relation to periodontal diseases in humans. J Periodont Res 1971;6:243-251.

Gross EL, Leys EJ, Gasparovich SR, Firestone ND, Schwartzbaum JA, Janies DA, Asnani K, Griffen AL: Bacterial 16S sequence analysis of severe caries in young permanent teeth. J Clin Microbiol 2010;48:4121-4128.

Huang X, Exterkate RA, Ten Cate JM: Factors associated with alkali production from arginine in dental biofilms. J Dent Res 2012;91:11301134.

Kleinberg I: Biochemistry of the dental plaque. Adv Oral Biol 1970;4:43-90.

Kleinberg I, Jenkins GN: The pH of dental plaques in the different areas of the mouth before and after meals and their relationship to the $\mathrm{pH}$ and rate of flow of resting saliva. Arch Oral Biol 1964;72:493-516.

Kopstein J, Wrong OM: The origin and fate of salivary urea and ammonia in man. Clin Sci Mol Med 1977;52:9-17.

-Kraivaphan P, Amornchat C, Triratana T, Mateo LR, Ellwood R, Cummins D, Devizio W, Zhang YP: Two-year caries clinical study of the efficacy of novel dentifrices containing $1.5 \%$ arginine, an insoluble calcium compound and 1,450 p.p.m. fluoride. Caries Res 2013;47:582-590.

Liu Y, Burne RA: Multiple two-component systems modulate alkali generation in Strepto- coccus gordonii in response to environmental stresses. J Bacteriol 2009;191:7353-7362.

Liu Y, Dong Y, Chen YY, Burne RA: Environmental and growth phase regulation of the Streptococcus gordonii arginine deiminase genes. Appl Environ Microbiol 2008;74:5023-5030.

Mager DL, Ximenez-Fyvie LA, Haffajee AD, Socransky SS: Distribution of selected bacterial species on intraoral surfaces. J Clin Periodontol 2003;30:644-654.

Margolis HC, Duckworth JH, Moreno EC: Composition and buffer capacity of pooled starved plaque fluid from caries-free and caries-susceptible individuals. J Dent Res 1988;67: 1476-1482.

Marquis RE: Oxygen metabolism, oxidative stress and acid-base physiology of dental plaque biofilms. J Ind Microbiol 1995;15:198-207.

- Marquis RE, Bender GR, Murray DR, Wong A: Arginine deiminase system and bacterial adaptation to acid environments. Appl Environ Microbiol 1987;53:198-200.

Nascimento MM, Gordan VV, Garvan CW, Browngardt CM, Burne RA: Correlations of oral bacterial arginine and urea catabolism with caries experience. Oral Microbiol Immunol 2009;24:89-95.

Nascimento MM, Liu Y, Kalra R, Perry S, Adewumi A, Xu X, Primosch RE, Burne RA. Oral arginine metabolism may decrease the risk for dental caries in children. J Dent Res 2013; 92:604-608.

- Paster BJ, Boches SK, Galvin JL, Ericson RE, Lau CN, Levanos VA, Sahasrabudhe A, Dewhirst FE: Bacterial diversity in human subgingival plaque. J Bacteriol 2001;183:3770-3783.

Peterson S, Woodhead J, Crall J: Caries resistance in children with chronic renal failure: plaque $\mathrm{pH}$, salivary $\mathrm{pH}$, and salivary composition. Pediatr Res 1985;19:796-799.

Rogers AH: Utilization of nitrogenous compounds by oral bacteria. Aust Dent J 1990;35: 468-471.

Russell RR: How has genomics altered our view of caries microbiology? Caries Res 2008;42:319327.

Schulte R, Burne RA, Gordan VV, Nascimento MM: Alkali generation capacity of oral bacteria (abstract 113). IADR/AADR/CADR 87th General Session, Miami, 2009.

Shu M, Morou-Bermudez E, Suarez-Perez E, Rivera-Miranda $C$, Browngardt CM, Chen YY, Magnusson I, Burne RA: The relationship between dental caries status and dental plaque urease activity. Oral Microbiol Immunol 2007;22:61-66. 
Sissons $\mathrm{CH}$, Hancock EM, Cutress TW: The source of variation in ureolysis in artificial plaques cultured from human salivary bacteria. Arch Oral Biol 1988a;33:721-726.

-Sissons CH, Hancock EM, Perinpanayagam HE, Cutress TW: The bacteria responsible for ureolysis in artificial dental plaque. Arch Oral Biol 1988b;33:727-733.

-Sissons CH, Wong L, Hancock EM, Cutress TW: The $\mathrm{pH}$ response to urea and the effect of liquid flow in 'artificial mouth' microcosm plaques. Arch Oral Biol 1994;39:497-505.

Srisilapanan P, Korwanich N, Yin W, Chuensuwonkul C, Mateo LR, Zhang YP, Cummins D, Ellwood RP: Comparison of the efficacy of a dentifrice containing $1.5 \%$ arginine and 1,450 p.p.m. fluoride to a dentifrice containing 1,450 p.p.m. fluoride alone in the management of early coronal caries as assessed using quantitative light-induced fluorescence. J Dent 2013;41:29-34.
Stephan RM: Changes in hydrogen-ion concentration on tooth surfaces and in carious lesions. J Am Dent Assoc 1940;27:718-723.

-Van Wuyckhuyse BC, Perinpanayagam HE, Bevacqua D, Raubertas RF, Billings RJ, Bowen WH, Tabak LA: Association of free arginine and lysine concentrations in human parotid saliva with caries experience. J Dent Res 1995; 74:686-690.

Vander Wauven C, Pierard A, Kley-Raymann M, Haas D: Pseudomonas aeruginosa mutants affected in anaerobic growth on arginine: evidence for a four-gene cluster encoding the arginine deiminase pathway. J Bacteriol 1984; 160:928-934.
Wijeyeweera RL, Kleinberg I: Arginolytic and ureolytic activities of pure cultures of human oral bacteria and their effects on the $\mathrm{pH}$ response of salivary sediment and dental plaque in vitro. Arch Oral Biol 1989;34:43-53.

Yin W, Hu DY, Fan X, Feng Y, Zhang YP, Cummins D, Mateo LR, Pretty IA, Ellwood RP: A clinical investigation using quantitative lightinduced fluorescence (QLF) of the anticaries efficacy of a dentifrice containing $1.5 \%$ arginine and 1,450 p.p.m. fluoride as sodium monofluorophosphate. J Clin Dent 2013a; 24(A):15-22.

Yin W, Hu DY, Li X, Fan X, Zhang YP, Pretty IA, Mateo LR, Cummins D, Ellwood RP: The anti-caries efficacy of a dentifrice containing $1.5 \%$ arginine and 1,450 p.p.m. fluoride as sodium monofluorophosphate assessed using quantitative light-induced fluorescence (QLF). J Dent 2013b;41:22-28. 